\title{
BIOLOGICAL SYNTHESIS OF NANOPARTICLES FROM MEDICINAL PLANTS AND ITS USES IN INHIBITING BIOFILM FORMATION
}

\author{
HARSHITA AGARWAL, MAHALINGAM GAYATHRI*
}

Department of Biotechnology, School of Bioscience and Technology, VIT University, Vellore - 632 014, Tamil Nadu, India. Email: gayathrigopinath@vit.ac.in

Received: 03 February 2017, Revised and Accepted: 01 March 2017

\begin{abstract}
Pathogenic micro-organisms have become the main problem in today's world. All microbes are getting resistant to antibiotics. This is due to the formation of biofilm layer above the micro-organisms. Learning the characteristics of biofilm can help us in treating the infectious disease induced via micro-organisms. They affect human's life in some or the other way. For example, the plaque formed in our teeth that cause tooth decay is due to the bacterial biofilm. When micro-organisms stick to moist or wet surfaces, it produces glue-like, slimy contents which are known as biofilms. Biofilms belong to the sessile communities, communities in which organisms are considered as immobile. Biofilms are enclosed within a matrix, known as extracellular polymeric matrix, which are secreted by micro-organisms. Biofilms attached to the surfaces are affected by certain characteristics like the growth medium, substratum to which it is attached and cellular surfaces. Each of these factors can either increase or decrease the hold of biofilm on the surfaces. With the help of biofilms, micro-organisms protect themselves from antibiotics and cause various infectious disease. Recent studies had proved medicinal plants to be effective in treating disease caused by microbes. Medicinal plants produce active compounds during secondary metabolism which help in the treatment of infectious disease. The problem that arises with antibiotics is that they are unable to penetrate through the biofilm. This problem is solved by converting antibiotics in nanoparticle size. Nanoparticles have high penetrating ability than the antibiotics. They help in controlling microbial growth by killing them.
\end{abstract}

Keywords: Medicinal plants, Nanoparticles, Biofilm.

(C) 2017 The Authors. Published by Innovare Academic Sciences Pvt Ltd. This is an open access article under the CC BY license (http://creativecommons. org/licenses/by/4. 0/) DOI: http://dx.doi.org/10.22159/ajpcr.2017.v10i5.17469

\section{INTRODUCTION}

Micro-organisms have developed resistance against antibiotics with the help of biofilms. Biofilms formed by micro-organisms, covers the microbes which prevent the passage of antibiotics and interferes with the interaction between antibiotics and micro-organisms. Biofilms are formed when micro-organisms get attached to the moist surface. After coming in contact to the moist surface, it produces gel-like, slimy substances. Micro-organisms encapsulate themselves in this slimy layer, which is known as biofilm. It is made up of extracellular polymeric matrix, produced by micro-organisms [3]. The lifestyle of micro-organisms changes completely on the formation of biofilm. The physiological changes have been observed in the microbes with the formation of biofilms. Biofilms increase the life span of micro-organisms. It also increases the microbial growth rate. Micro-organisms enter inside the host and combat its innate immune defense system with the help of biofilm [8]. Hence, biofilm increases the persistence period of microorganisms inside the host. Biofilm has the complex structure which reduces the attacking ability of antibiotics. It protects micro-organisms from the attack of antibiotics as it does not allow antibiotics to reach microbial surface [11]. Experiments have been performed which shows that Staphylococcus aureus has become resistant to methicillin as it is covered by biofilms [1]. Polysaccharides, such as silica acid, help in protecting micro-organisms by inhibiting the attack of neutrophils toward microbes. Thus, pathogens which were once considered as extracellular are converted into intracellular with the help of biofilm. It helps microbes to penetrate inside the host [10] (Figs. 1 and 2).

Therapeutics plants have the rich assets of ingredients which are utilized for the development of drugs. There are 8000 species of plants in India which are designated as medicinal plants. Medicinal plants have proved to be the best for the treatment of disease [2]. During secondary metabolism, medicinal plants secrete active compounds which have been helpful in treating infectious disease. Medicinal plants have been used for the extraction, synthesis, and development of drugs. Extracts of methanol and ethanol from the medicinal plants have been studied and it has proved to be effective in treating biofilm and thus, the pathogens [16].

The objective of most of the conventional treatment is to kill or repress the growth of micro-organisms. Continuous exposures to these treatments make micro-organisms resistant toward them. This method affects pathogenic microbes only for a limited period. It has been observed that many pathogenic micro-organisms start developing resistant against such treatment after certain period [9]. It is because of the virulent factor that they produce during the treatment which makes them resistant. One such virulent factor is biofilm. Biofilm helps bacteria in fighting against the antibiotics treatment and immune system response. Thin, slimy layers of microbes that occur in moist environment are considered as biofilms. Biofilms are impermeable in nature which prevents the passage of antibiotics into the microbes. It has become important to develop new methods or medicines to treat micro-organisms that cause infectious disease. Nanotechnology has proved to be a standout among the most dynamic regions of research and development in advanced medical science. Nanoparticle is the most essential part of nanotechnology. It has proved to be effective in treating many diseases [5].

Nanoparticles are made up of both natural and inorganic materials. Nanoparticles made up from these materials have antibiofilm and antibacterial properties. Experiments have been performed and it has been proved that these nanoparticles can be used for the development of drugs which can be used for the treatment of biofilms. This proves that nanoparticle has different mechanisms to control biofilm growth and also different strategies to stop microbial growth and kill them. When the biofilms are treated with nanoparticles, it gets destroyed [20].

The interaction between nanoparticle and biofilm are as follows:

- Nanoparticle is transferred to the biofilm surface

- Nanoparticle gets attached to the surface 
- Nanoparticles penetrate through the biofilm surface toward the micro-organisms [18].

In other words, nanoparticles penetrate into biofilm layer, spoil cell physiology, denature protein, stop the activity of enzymes, and prevent the replication of DNA and interaction of ribosomes [17]. Many factors influence the interaction that occurs between biofilm and nanoparticle. They are physiochemical and biological factors of the biofilm matrix, environmental factors such as water and temperature (Fig. 3).

\section{MEDICINAL PLANTS}

\section{Panax ginseng}

P. ginseng is a therapeutic plant. It has a wide range of pharmacological applications. It contains an active ingredient, ginsenosides, which is useful in treating many infectious diseases. It has been used to treat cancer, neurodegenerative disease, diabetes mellitus, and hypertension. It helps in maintaining the homeostasis of immune system and regulates immune system against microbial attack [7]. Ginseng plants show many properties such as antimicrobial, antibacterial and antiviral properties. This plant was used for the synthesis of gold and silver nanoparticles [36]. These nanoparticles were formed by the reduction of auric chloride and silver nitrate, respectively, and they have been studied and found to be resistant toward biofilm produced by microbes. Silver nanoparticles showed inhibition against biofilm produced by $S$. aureus and Pseudomonas aeruginosa. Both gold and silver nanoparticles were also found to have anticoagulant properties [22] (Table 1 and Fig. 4).

\section{Dioscorea bulbifera}

There are 600 species under genus Dioscorea. Among them, D. bulbifera is a novel plant due to its species-specific phytochemistry. Tuber

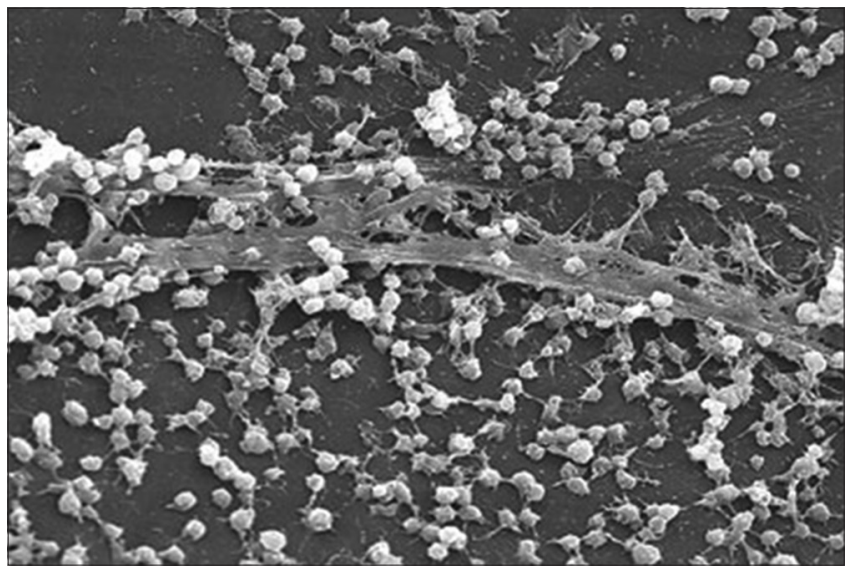

Fig. 1. Staphylococcus aureus biofilm on a moist surface. Source: http://science.howstuffworks.com/life/cellularmicroscopic/biofilm4.htm

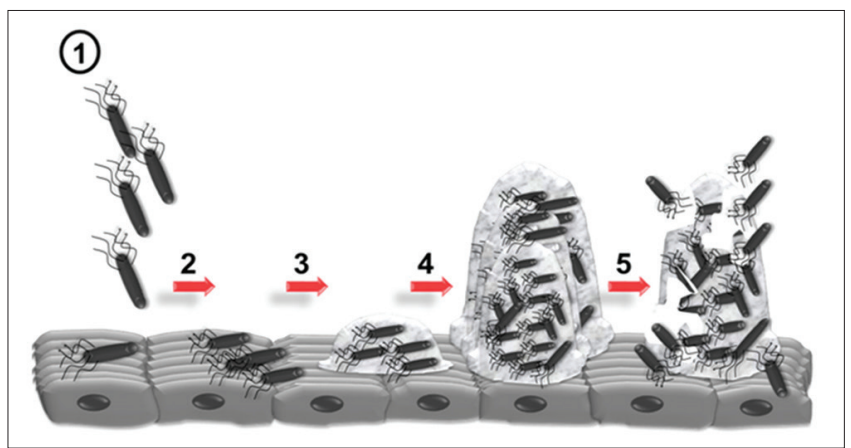

Fig. 2: Stages of biofilm development (1) reversible stage

(2) attachment stage (3) formation of biofilm (4) biofilms mature (5) detachment stage. Source: http://www.formatex.info/ microbiology4/vol1/179-187.pdf extract of the plant is rich in flavonoids and catechin which provides plant antioxidant and antidiabetic properties. Biofilm compounds of this plant show anti-inflammatory, plasmid curing, anticancer, and antidiabetic properties [4]. Aucore Ag shell nanoparticle was synthesized using the tuber extracts from $D$. bulbifera. These nanoparticles showed highest biofilm inhibition. This leads to the death of cells [19] (Table 2 and Fig. 5).

\section{Drosera binata}

$S$. aureus is a widely recognized infectious disease which causes skin infection, burn wounds and are resistant to antibiotics. Drug resistance is deadly dispute evolving in today's world. Recently, microbes resistant to antibiotics are controlled by multi-drug treatments.

Table 1: Classification of Panax ginseng

\begin{tabular}{ll}
\hline Kingdom & Plantae \\
\hline Order & Apiales \\
Family & Araliaceae \\
Genus & Panax \\
Species & Panax ginseng \\
\hline
\end{tabular}

Table 2: Classification of Dioscorea bulbifera

\begin{tabular}{ll}
\hline Kingdom & Plantae \\
\hline Order & Dioscoreales \\
Family & Dioscoreaceae \\
Genus & Dioscorea \\
Species & Dioscorea bulbifera \\
\hline
\end{tabular}

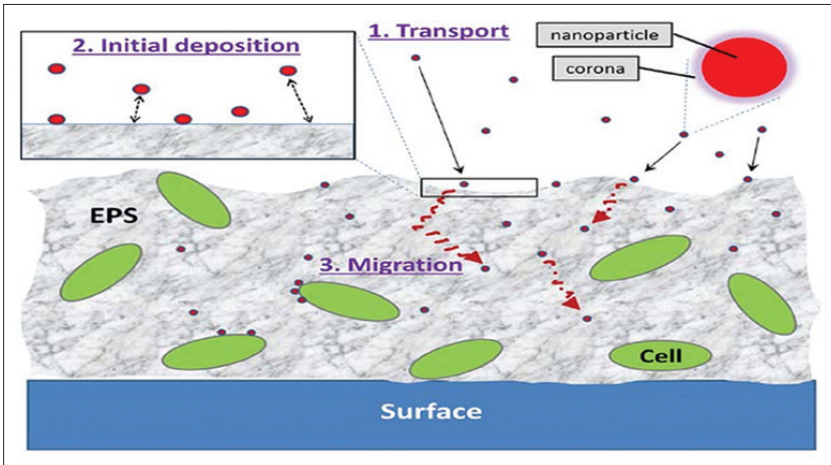

Fig. 3: Nanoparticle penetrating through the biofilm layer and migrating toward bacterial surface. Source: http://journal. frontiersin.org/article/10.3389/fmicb.2015.00591/full

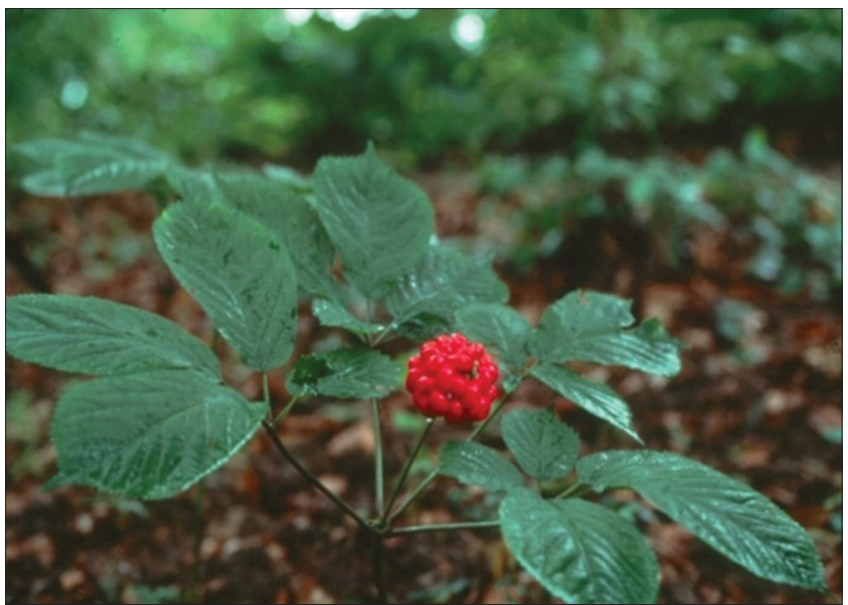

Fig. 4: Medicinal plant Panax ginseng. Source: http://www.herbs.org/greenpapers/ginseng.htm 
In vitro extraction of secondary metabolites from $D$. binata is potent antibacterial agent against $S$. aureus. It disrupts the biofilm layer of bacteria. Silver nanoparticle obtained from the extract of $D$. binata is effective in antibactericidal activity. They do not have any cytotoxic impacts on human keratinocytes [15] (Table 3 and Fig. 6).

\section{Plumbago zeylanica}

P. zeylanica belongs to genus Plumbago exhibits multiple medicinal properties such as anti-inflammatory, wound healing, antidiabetic, memory inducing, blood coagulation, antimalarial, central nervous system, microbiological, anticancer, antiviral, and antioxidant activities [12]. Root extract of $P$. zeylanica contains sugars, flavonoids, and organic acid. Bimetallic, gold and silver nanoparticles were developed using the root extract of the plant. These nanoparticles affect biofilms produced by $S$. aureus, Acinetobacter baumannii, and Escherichia coli. They showed antimicrobial and antibiofilm properties against these microbes [13] (Table 4 and Fig. 7).

\section{Ruta graveolens}

$R$ graveolens comes under the genus Ruta. $R$. graveolens contains acridone alkaloids, flavonoids, coumarines, terpenoids, and volatile substances which give the plant antiandrogenic activity, antiinflammatory and analgesic properties and anticancer activities [6] (Table 5 and Fig. 8). Silver nanoparticles obtained from R. graveolens shows color change on phytochemical reaction. It also shows antibacterial and antibiofilm activity against Candida albicans, S. aureus, and P. aeruginosa [14] (Table 6).

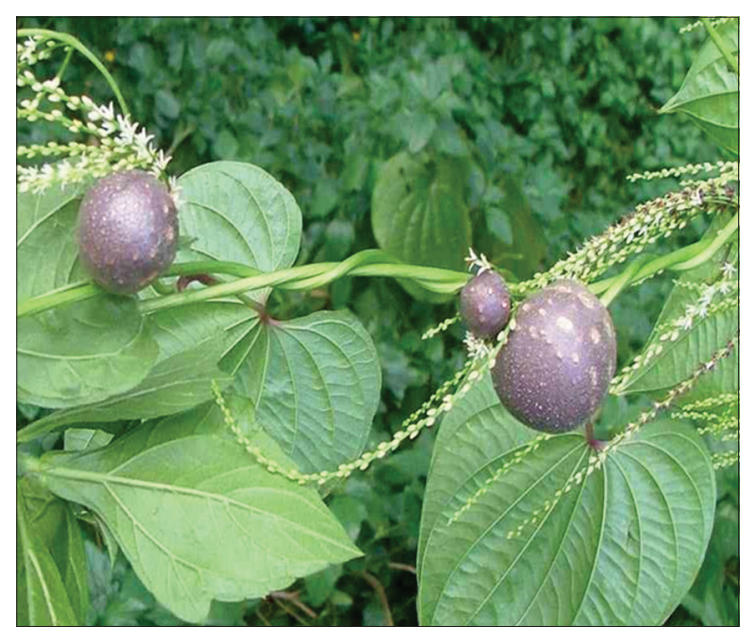

Fig. 5: Medicinal plant Dioscorea bulbifera. Source: https://keyserver.lucidcentral.org/weeds/data/media/ Html/dioscorea_bulbifera_var__bulbifera.htm

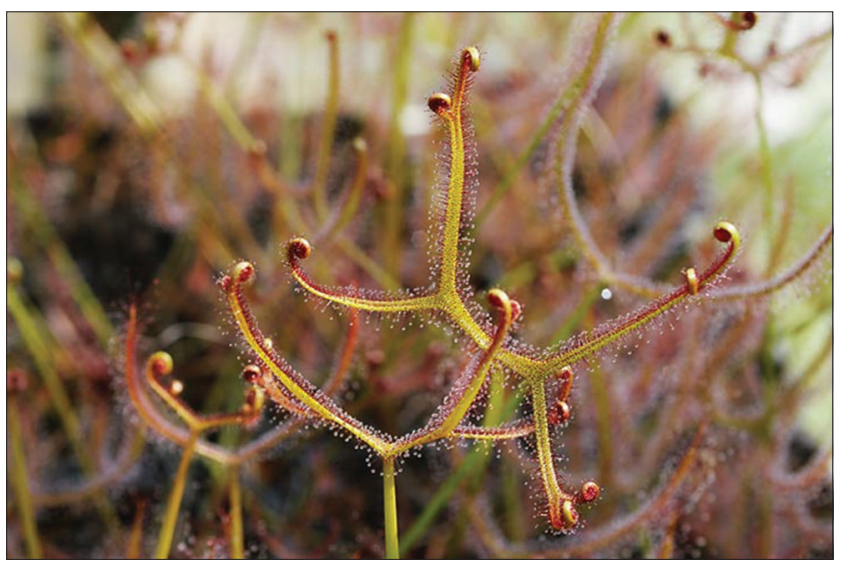

Fig. 6: Medicinal plant Drosera binate. Source: http:// cpphotofinder.com/drosera-binata-var-dichotoma-2539.html
Table 3: Classification of Drosera binata

\begin{tabular}{ll}
\hline Kingdom & Plantae \\
\hline Order & Caryophyllales \\
Family & Droseraceae \\
Genus & Drosera \\
Species & Drosera binata \\
\hline
\end{tabular}

Table 4: Classification of Plumbago zeylanica

\begin{tabular}{ll}
\hline Kingdom & Plantae \\
\hline Order & Caryophyllales \\
Family & Plumbaginaceae \\
Genus & Plumbago \\
Species & Plumbago zeylanica \\
\hline
\end{tabular}

Table 5: Classification of Ruta graveolens

\begin{tabular}{ll}
\hline Kingdom & Plantae \\
\hline Order & Sapindales \\
Family & Rutaceae \\
Genus & Ruta \\
Species & Ruta graveolens \\
\hline
\end{tabular}

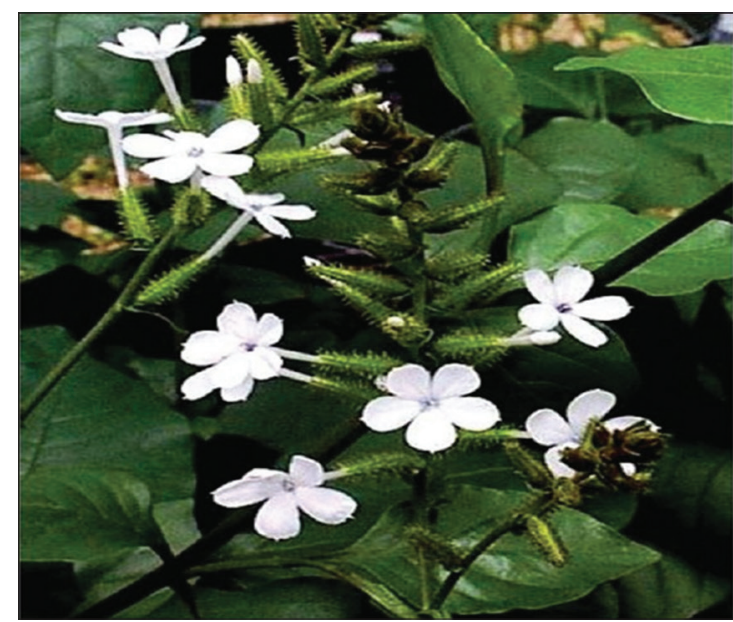

Fig. 7: Medicinal plants Plumbago zeylanica Source: http://cysonline.org/article.asp?issn=2229-5186;year= 2012; ;olume $=3$; issue $=3$; spage $=178$; epage $=1$ 198; ; aulast $=$ Kishore

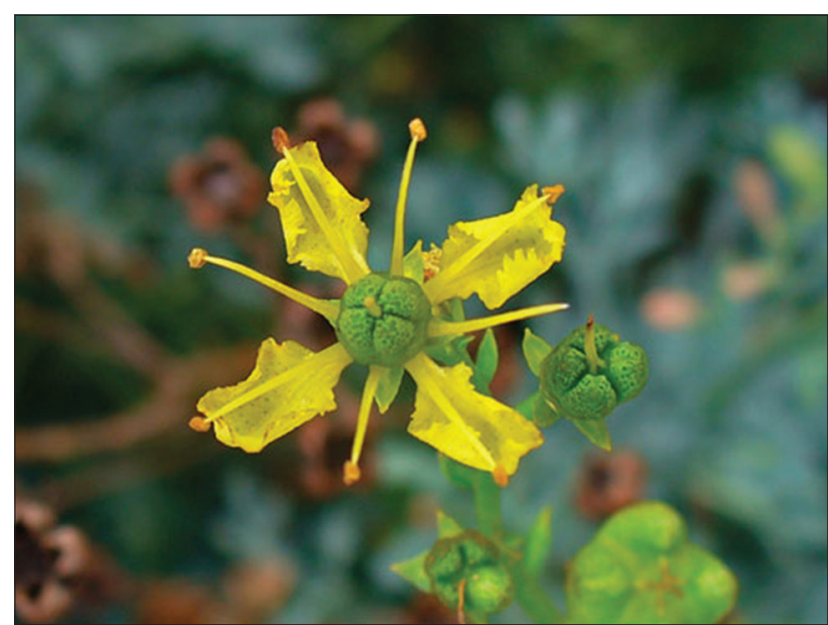

Fig. 8: Medicinal plant Ruta graveolens.

Source: http://www.motherearthliving.com/In-the-Garden/rutagraveolens-growing-common-rue 
Table 6: Activities of medicinal plants in form of nanoparticles

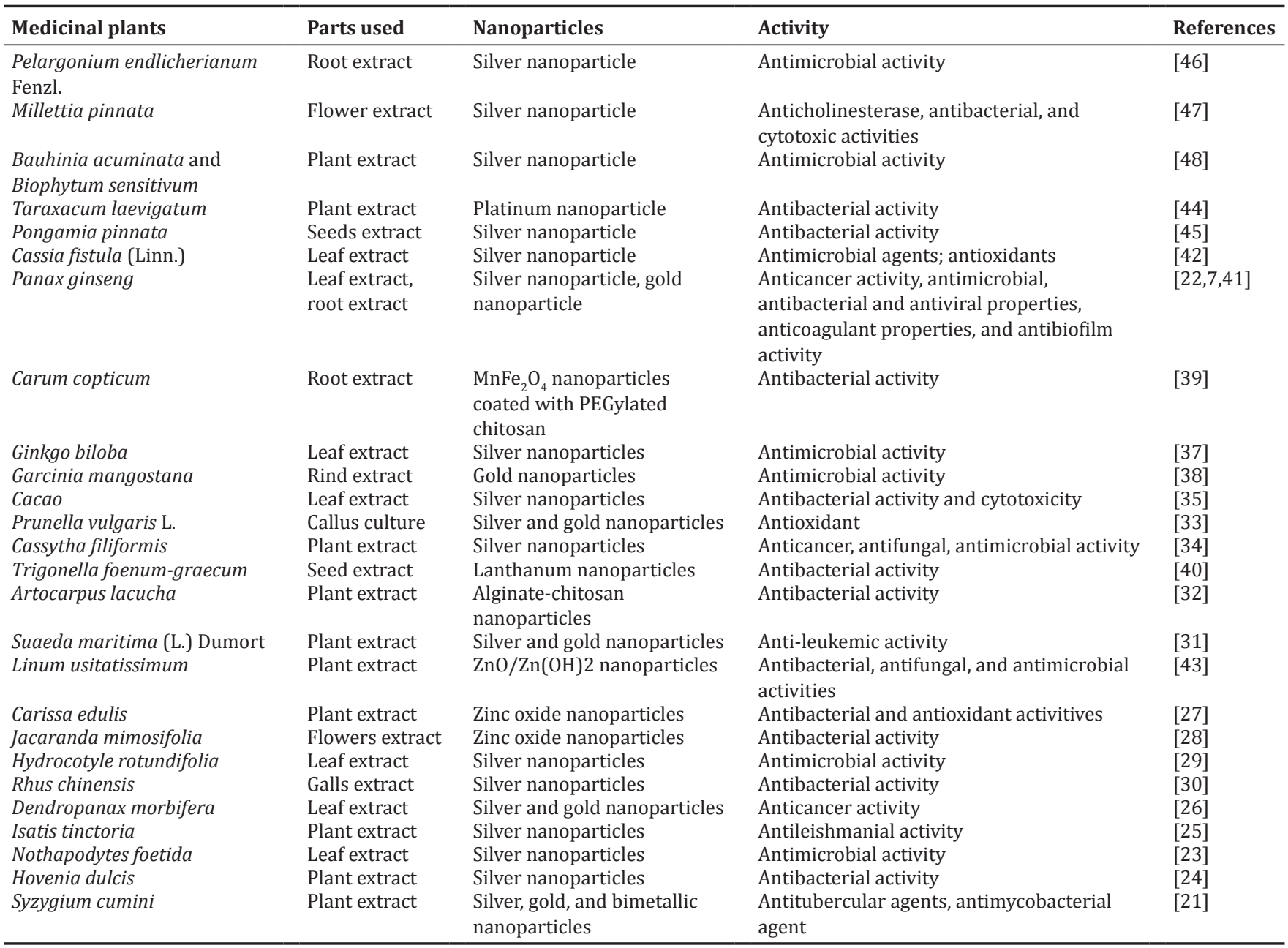

\section{CONCLUSION}

Biofilms produced by micro-organisms are accountable for the spread of infectious disease. Biofilms have high resistance against the antibiotics which has become threat to the human beings. It is because the biofilm restrict the penetration of antibiotics and thus prevents the killing of micro-organisms. Nanoparticles made up of medicinal plants have been observed to be helpful in killing micro-organisms. It has proved to be very significant in treating infectious disease. They have the high penetrating power which helps them to penetrate into the biofilm layer and attack microbial surface. It has been observed that a nanoparticle does not affect any organs when treated to eliminate infectious disease. Nanoparticle increases the efficiency of antibiotics and it not only has antibiofilm activity but also antibacterial, antimicrobial, anticancer, and antioxidant activities.

\section{REFERENCES}

1. Chambers HF, Deleo FR. Waves of resistance: Staphylococcus aureus in the antibiotic era. Nat Rev Microbiol 2009;7(9):629-41.

2. Silva NC, Júnior AF. Biological properties of medicinal plants: A review of their antimicrobial activity. J Venom Anim Toxins Incl Trop Dis 2010;16(3):402-13.

3. Namasivayam SK, Preethi M, Bharani RS, Robin G, Latha B. Biofilm inhibitory effect of silver nanoparticles coated catheter against Staphylococcus aureus and evaluation of its synergistic effects with antibiotics. Int J Biol Pharm Res 2012;3(2):259-65.

4. Ghosh S, Patil S, Ahire M, Kitture R, Kale S, Pardesi K, et al. Synthesis of silver nanoparticles using Dioscorea bulbifera tuber extract and evaluation of its synergistic potential in combination with antimicrobial agents. Int J Nanomed 2012;7:483-96.
5. Chaudhari PR, Masurkar SA, Shidore VB, Kamble SP. Effect of biosynthesized silver nanoparticles on Staphylococcus aureus biofilm quenching and prevention of biofilm formation. Nano Micro Lett 2012;4(1):34-9.

6. Asgarpanah J, Khoshkam R. Phytochemistry and pharmacological properties of Ruta graveolens L. J Med Plants Res 2012;6(23):3942-9.

7. Kang S, Min H. Ginseng, the 'Immunity boost': The effects of Panax ginseng on immune system. J Ginseng Res 2012;36(4):354-68.

8. Gautam CK, Srivastav AK, Bind S, Madhav M, Shanthi V. An insight into biofilm ecology and its applied aspects. Int J Pharm Pharm Sci 2013;5(4):69-73

9. Namasivayam SK, Roy EA. Anti-biofilm effect of medicinal plant extracts against clinical isolate of biofilm of Escherichia coli. Int J Pharm Pharm Sci 2013;5(2):486-9.

10. Kostakioti M, Hadjifrangiskou M, Hultgren SJ. Bacterial biofilms: Development, dispersal, and therapeutic strategies in the dawn of the postantibiotic era. Cold Spring Harb Perspect Med 2013;3(4):a010306.

11. Chen M, Yu Q, Sun H. Novel strategies for the prevention and treatment of biofilm related infections. Int J Mol Sci 2013;14(9):18488-501.

12. Jain P, Sharma HP, Basri F, Baraik B, Kumari S, Pathak C. Pharmacological profiles of ethno-medicinal plant: Plumbago zeylanica Linn. A review. Int J Pharm Sci Rev Res 2014;24(1):157-63.

13. Salunke GR, Ghosh S, Santosh Kumar RJ, Khade S, Vashisth P, Kale T, et al. Rapid efficient synthesis and characterization of silver, gold, and bimetallic nanoparticles from the medicinal plant Plumbago zeylanica and their application in biofilm control. Int $\mathbf{J}$ Nanomedicine 2014;9:2635-53.

14. Sivakamavalli J, Deepa O, Vaseeharan B. Discrete nanoparticles of Ruta graveolens induces the bacterial and fungal biofilm inhibition. Cell Commun Adhes 2014;21(4):229-38.

15. Krychowiak M, Grinholc M, Banasiuk R, Krauze-Baranowska M, Glód D, Kawiak A, et al. Combination of silver nanoparticles and 
Drosera binata extract as a possible alternative for antibiotic treatment of burn wound infections caused by resistant Staphylococcus aureus. PLoS One 2014;9(12):e115727.

16. Singh R. Medicinal plants: A review. J Plant Sci 2015;3(1-1):50-5

17. Singh R, Shedbalkar UU, Wadhwani SA, Chopade BA. Bacteriagenic silver nanoparticles: Synthesis, mechanism, and applications. Appl Microbiol Biotechnol 2015;99(11):4579-93.

18. Ikuma K, Decho AW, Lau BL. When nanoparticles meet biofilmsinteractions guiding the environmental fate and accumulation of nanoparticles. Front Microbiol 2015;6:591.

19. Ghosh S, Jagtap S, More P, Shete UJ, Maheshwari NO, Rao SJ, et al. Dioscorea bulbifera mediated synthesis of novel $\mathrm{Au}_{\text {core }} \mathrm{Ag}_{\text {shell }}$ nanoparticles with potent antibiofilm and antileishmanial activity. J Nanomater 2015;2015:12.

20. Singh R, Nadhe S, Wadhwani S, Shedbalkar U, Chopade BA. Nanoparticles for control of biofilms of Acinetobacter Species. Materials 2016;9(5):383.

21. Singh R, Nawale L, Arkile M, Wadhwani S, Shedbalkar U, Chopade S, et al. Phytogenic silver, gold, and bimetallic nanoparticles as novel antitubercular agents. Int J Nanomedicine 2016;11:1889-97.

22. Singh P, Kim YJ, Wang C, Mathiyalagan R, Yang DC. The development of a green approach for the biosynthesis of silver and gold nanoparticles by using Panax ginseng root extract, and their biological applications. Artif Cells Nanomed Biotechnol 2016;44(4):1150-7.

23. Roopesh R, Geedhika G, D'Souza J, Anandhan S, Bhat KU, Jaya MJ, et al. Optimised microwave-assisted biosynthesis of silver nanoparticles from Nothapodytes foetida leaf extracts and its anti-microbial activities. J Exp Nanosci 2016;11(11):840-52.

24. Salunke BK, Sawant SS, Kim BS. Enhancement of antibacterial effect by biosynthesized silver nanoparticles with antibiotics. J Nanosci Nanotechnol 2016;16(7):7191-4.

25. Ahmad A, Wei Y, Syed F, Khan S, Khan GM, Tahir K, et al. Isatis tinctoria mediated synthesis of amphotericin B-bound silver nanoparticles with enhanced photoinduced antileishmanial activity: A novel green approach. J Photochem Photobiol B Biol 2016;161:17-24.

26. Wang C, Mathiyalagan R, Kim YJ, Castro-Aceituno V, Singh P, Ahn S, et al. Rapid green synthesis of silver and gold nanoparticles using Dendropanax morbifera leaf extract and their anticancer activities. Int J Nanomedicine 2016;11:3691-701.

27. Fowsiya J, Madhumitha G, Al-Dhabi NA, Arasu MV. Photocatalytic degradation of Congo red using Carissa edulis extract capped zinc oxide nanoparticles. J Photochem Photobiol B 2016;162:395-401.

28. Sharma D, Sabela MI, Kanchi S, Mdluli PS, Singh G, Stenström TA, et al. Biosynthesis of $\mathrm{ZnO}$ nanoparticles using Jacaranda mimosifolia flowers extract: Synergistic antibacterial activity and molecular simulated facet specific adsorption studies. J Photochem Photobiol B Biol 2016;162:199-207.

29. Kumari R, Brahma G, Rajak S, Singh M, Kumar S. Antimicrobial activity of green silver nanoparticles produced using aqueous leaf extract of Hydrocotyle rotundifolia. Orient Pharm Exp Med 2016;16(3):195-201.

30. Patil MP, Rokade AA, Ngabire D, Kim GD. Green synthesis of silver nanoparticles using water extract from galls of Rhus Chinensis and its antibacterial activity. J Cluster Sci 2016;27(5):1737-50.

31. Rajendran N, Subramaniam S, Raja MR, Brindha P, Kar Mahapatra S, Sivasubramanian A. Plant phenyl-propanoids-conjugated silver nanoparticles from edible plant Suaeda maritima (L.) dumort. Inhibit proliferation of K562-human myeloid leukemia cells. Artif Cells Nanomed Biotechnol 2016:1-7.

32. Kaewkod T, Tragoolpua K, Tragoolpua Y. Encapsulation of Artocarpus lacucha Roxb. Extract in alginate chitosan nanoparticles for inhibition of methicillin resistant Staphylococcus aureus and bacteria causing skin diseases. Chiang Mai J Sci 2016;43(5):946-58.
33. Fazal H, Abbasi BH, Ahmad N, Ali M. Elicitation of medicinally important antioxidant secondary metabolites with silver and gold nanoparticles in callus cultures of Prunella vulgaris L. Appl Biochem Biotechnol 2016;180(6):1076-92.

34. Jena S, Singh RK, Panigrahi B, Suar M, Mandal D. Photo-bioreduction of $\mathrm{Ag}+$ ions towards the generation of multifunctional silver nanoparticles: Mechanistic perspective and therapeutic potential. J Photochem Photobiol B 2016;164:306-13

35. Chowdhury NR, MacGregor-Ramiasa M, Zilm P, Majewski P, Vasilev K. 'Chocolate' silver nanoparticles: Synthesis, antibacterial activity and cytotoxicity. J Colloid Interface Sci 2016;482:151-8.

36. Singh P, Kim YJ, Yang DC. A strategic approach for rapid synthesis of gold and silver nanoparticles by Panax ginseng leaves. Artif Cells Nanomed Biotechnol 2016;44:1949-1957.

37. Nishanthi R, Palani P. Green Synthesis of Gold Nanoparticles from the Rind Extract of Garcinia mangostana and its Synergistic Effect with Antibiotics Against Human Pathogenic Bacteria. 16 ${ }^{\text {th }}$ International Conference on Nanotechnology-IEEE Nano 2016. 21 November 2016. p. 431-4.

38. Ren YY, Yang H, Wang T, Wang C. Green synthesis and antimicrobial activity of monodisperse silver nanoparticles synthesized using Ginkgo biloba leaf extract. Phys Lett A 2016;380(45):3773-7.

39. Esmaeili A, Ghobadianpour S. Antibacterial activity of Carum copticum extract loaded MnFe2O4 nanoparticles coated with PEGylated chitosan. Ind Crop Prod 2016;91:44-8.

40. Chakraborty P, Dam D, Abraham J. Bioactivity of lanthanum nanoparticle synthesized using Trigonella foenum-graecum seed extract. J Pharm Sci Res 2016;8(11):1253-7.

41. Castro-Aceituno V, Ahn S, Simu SY, Singh P, Mathiyalagan R, Lee HA, et al. Anticancer activity of silver nanoparticles from Panax ginseng fresh leaves in human cancer cells. Biomed Pharmacother 2016;84:158-165

42. Mohanta YK, Panda SK, Biswas K, Tamang A, Bandyopadhyay J, De $\mathrm{D}$, et al. Biogenic synthesis of silver nanoparticles from Cassia fistula (Linn.): In vitro assessment of their antioxidant, antimicrobial and cytotoxic activities. IET Nanobiotechnol 2016;10(6):438-44.

43. Ghaedi M, Yousefi-Nejad M, Safarpoor M, Hashemi S, Goudarzi A, Tyagi I, et al. Investigation of phytochemical and antimicrobial properties of Linum usitatissimum in presence of $\mathrm{ZnO} / \mathrm{Zn}(\mathrm{OH})$ nanoparticles and extraction of euphol from Euphorbia microsciadia. Desalination Water Treat 2016;57(43):20597-607.

44. Tahir K, Nazir S, Ahmad A, Li B, Khan AU, Khan ZU, et al. Facile and green synthesis of phytochemicals capped platinum nanoparticles and in vitro their superior antibacterial activity. J Photochem Photobiol B Biol 2017; 166:246-51.

45. Beg M, Maji A, Mandal AM, Das S, Aktara MN, Jha PK, Hossain M. Green synthesis of silver nanoparticles using Pongamia pinnata seed: Characterization, antibacterial property, and spectroscopic investigation of interaction with human serum albumin. J Mol Recognit 2017;30(1):e2565.

46. Seker Karatoprak G, Aydin G, Altinsoy B, Altinkaynak C, Kosar M, Ocsoy I. The effect of Pelargonium endlicherianum Fenzl. root extracts on formation of nanoparticles and their antimicrobial activities. Enzyme Microb Technol 2017;97:21-6

47. Rajakumar G, Gomathi T, Thiruvengadam M, Rajeswari VD, Kalpana VN, Chung IM. Evaluation of anti-cholinesterase, antibacterial and cytotoxic activities of green synthesized silver nanoparticles using from Millettia pinnata flower extract. Microb Pathog 2017;103:123-8.

48. Antony E, Sathiavelu M, Arunachalam S. Synthesis of silver nanoparticles from the medicinal plant Bauhinia acuminate and Biophytum sensitivum-A comparative study of its biological activities with plant extract. Int J Appl Pharm 2017;9(1):22-9. 